\title{
Oordelen over personenschade veroorzaakt door diagnostische fouten
}

\author{
Prof.dr. R.W.M. Giard*
}

\begin{abstract}
1. Inleiding
Personenschade door foutief medisch handelen kan het gevolg zijn van hetzij therapeutische, hetzij diagnostische interventies. Jarenlang voerden schadeclaims over onjuiste medische behandelingen de boventoon. Meestal ging het daarbij om verkeerd uitgevoerde ingrepen, onvoldoende bewaking van de patiënt tijdens en na de ingreep, het niet tijdig herkennen van complicaties of medicatiefouten. In een recente kroniek over medische aansprakelijkheid domineren nog steeds de therapeutische interventies. ${ }^{1}$ Zo ook in een onlangs verschenen proefschrift over onbedoelde zorggerelateerde schade. ${ }^{2} \mathrm{De}$ laatste jaren echter is er een verschuiving merkbaar, want steeds meer schadeclaims gaan over diagnostische fouten. Diverse onderzoeken in de Verenigde Staten hebben laten zien dat momenteel vaak al meer dan de helft van de schadeclaims vermeende diagnostische fouten betreft. Ook blijkt dat de toegewezen schadebedragen bij diagnostische claims gemiddeld hoger liggen dan bij therapeutische. ${ }^{3}$ Cijfers over dergelijke trends zijn in Nederland nog nauwelijks voorhanden, maar deze internationale tendens zal zeker niet aan ons voorbijgaan.
\end{abstract}

Bij het vaststellen van onrechtmatig handelen door de arts zal civielrechtelijk de open norm van artikel 7:453 van het Burgerlijk Wetboek (BW) worden gebruikt: was dit de zorg van een goed hulpverlener? De tuchtrechtelijke norm van artikel 47 lid 1 van de Wet op de beroepen in de individuele gezondheidszorg (Wet BIG) is in essentie hetzelfde. Waarin onderscheiden diagnostische fouten zich qua beoordeling binnen een juridische context nu wezenlijk van therapeutische? Daarover gaat dit artikel. De beoordeling van de tekortkoming in de nakoming van de zorgplicht, de schade en het causale verband vragen elk om een specifiek inzicht wanneer, hoe en waarom dergelijke diagnostische fouten worden gemaakt. Een diagnose stellen is primair een mentale daad en een fout ont-

* Prof. dr. R.W.M. Giard is jurist en arts. Hij is hoogleraar methodologie en aansprakelijkheid aan de Erasmus School of Law van de Erasmus Universiteit Rotterdam.

1. M.J.J. de Ridder, Kroniek rechtspraak civiel recht, Tijdschrift voor Gezondheidsrecht (37) 2013, afl. 6, p. 543-564.

2. R.P. Wijne, Aansprakelijkheid voor zorggerelateerde schade (diss. Rotterdam), Den Haag: Boom Juridische uitgevers 2013.

3. A.S. Tehrani e.a., 25-year summary of US malpractice claims for diagnostic errors 1986-2010: An analysis from the National Practitioner Data Bank, Quality and Safety in Health Care (22) 2013, p. 672-680 en N. Sevdalis e.a., Diagnostic error in a national incident reporting system in the UK, Journal of Evaluation in Clinical Practice (16) 2010, afl. 6, p. 1276-1281. staat steeds door een samenspel van persoonlijke, contextuele en organisatorische factoren en vraagt daarom een breed en diepgaand onderzoek.

Een patiënt die met de gevolgen van een diagnostische fout geconfronteerd wordt, zal daarvoor een verklaring zoeken. Bij medische aansprakelijkheid bestaat steeds het gevaar van de fundamentele attributiefout ('het is de schuld van de arts'), waardoor er te veel naar de persoon van de arts wordt gekeken en te weinig naar de overige factoren die tevens bepalend zijn voor de afloop. ${ }^{4}$ Die causale percepties van de gelaedeerde spelen van meet af aan een belangrijke rol en ze beïnvloeden het feitenonderzoek en het oordeel..$^{5}$ Beter inzicht in de vraag hoe en waarom diagnostische fouten worden gemaakt, helpt om die kwestie beter en daardoor objectiever te beoordelen en kan daardoor de preventiefunctie van het aansprakelijkheidsrecht versterken.

\section{Het diagnostische proces}

Wie zich met een gezondheidsprobleem tot een arts wendt, heeft drie vragen:

1. Wat is er met me aan de hand?

2. Bestaat er een behandeling voor die me beter zal maken?

3. Zal ik ook volledig kunnen genezen?

Dat vereist drie verschillende bekwaamheden: die van diagnost, therapeut en prognost. Binnen deze triade is het welslagen van de diagnose bepalend voor de kwaliteit van de overige twee. ${ }^{6}$ Daarom kunnen de gevolgen van een foute diagnose ook zo groot zijn.

\subsection{Het diagnostische arsenaal}

De start van de diagnostiek wordt bepaald door het door de patiënt aan de hulpverlener gepresenteerde probleem. De arts stelt vervolgens vragen, verricht lichamelijk onderzoek, vraagt nadere onderzoeken aan, verzamelt en interpreteert alle uitkomsten, en komt zo uiteindelijk tot de diagnose. Dit diagnostische proces kan heel kort zijn, waarbij de arts in één oogopslag vaststelt wat er aan de hand is, maar ook zeer complex,

4. R.W.M. Giard, Na de calamiteit: perceptie en primaire psychologische reacties en hun betekenis voor het aansprakelijkheidsrecht, Letsel \& Schade 2010, afl. 2, p. 6-12.

5. R.W.M. Giard, 'Dit had niet hoeven gebeuren.' De causale verklaring van ongewenste gebeurtenissen en de betekenis van de contrafeitelijke denkfout voor het CSQN-verband, NTBR (17) 2011, p. 471-478.

6. G. Dhaliwal \& A.S. Detsky, The evolution of the master diagnostician, JAMA (310) 2013, afl. 6, p. 579-580. 
waarbij nog verdere specialistische diagnostiek, met een keuze uit radiodiagnostisch onderzoek, klinisch-pathologisch onderzoek van cel- of weefselmonsters, infectiologisch onderzoek, genetisch of immunologisch onderzoek, noodzakelijk is. Het diagnostische proces verloopt bijgevolg vaak in meerdere stappen, waarbij uitkomsten van het eerste onderzoek de vervolgonderzoeken weer sturen. Er is zowel een start- als een stoppunt van het diagnostische proces aanwijsbaar.

Het woord 'test' wordt gebruikt voor elke vorm van verzamelen van diagnostische informatie, bijvoorbeeld het stellen van vragen, lichamelijk onderzoek, het doen van laboratoriumonderzoek of het maken van een röntgenfoto. Er bestaat helaas geen enkele perfecte test, en dus is geen enkele vorm van diagnostiek $100 \%$ accuraat en zijn misclassificaties obligaat. Dat heeft te maken met de uiteenlopende manieren waarop eenzelfde ziekte zich met klachten en symptomen kan openbaren; soms zijn die zo gering of atypisch dat het signaal gewoon niet door de test wordt opgepikt. Ook kunnen verschillende ziekten elkaar qua verschijnselen overlappen, waardoor klachten of ziekteverschijnselen onvoldoende specifiek voor één ziekte zijn. Ten slotte is geen enkele test perfect en heeft elke test zijn intrinsieke beperkingen, met foute uitkomsten als gevolg.

Bij elke test is er daarom steeds de mogelijkheid dat deze de ziekte mist (een foutnegatief resultaat) of vals alarm slaat (een foutpositief resultaat). Het testresultaat biedt derhalve nimmer absolute zekerheid over de ziektetoestand van de patiënt. ${ }^{7}$ Die ongewisheid verschilt van test tot test en kan worden gekwantificeerd door middel van twee basale kenmerken: de gevoeligheid (= sensitiviteit) van de test - de kans dat de test de ziekte inderdaad ontdekt - en de specificiteit - de kans dat de test normaal is bij afwezigheid van ziekte. Op zoek naar borstkanker bijvoorbeeld ontdekt een mammografie maar ongeveer $85 \%$ van de kwaadaardige tumoren, dat is de sensitiviteit van die test. Een hiv-test is normaal bij 99,7\% van de niet-geïnfecteerden, de specificiteit ervan. Dat betekent dat wanneer er duizend mensen die geen hiv hebben, worden getest, er drie een foutpositieve uitslag zullen krijgen.

Een belangrijk punt - ook juridisch - is dat een test voor twee essentieel verschillende doeleinden kan worden gebruikt: het aantonen van ziekte of juist het uitsluiten ervan. Dan worden er verschillende eisen aan een test gesteld. Willen we ziekte met een hoge mate van zekerheid uitsluiten, dan zal daarvoor een zeer gevoelige test moeten worden gebruikt met een lage kans op foutnegatieve uitslagen. Bij een retrospectieve beoordeling van een vermeende fout rijst daarom steeds de vraag waarvoor deze test bedoeld was: het aantonen of bovenal het uitsluiten van ziekte? Dit punt komen we later nog tegen, want veel claims gaan over een gemiste diagnose.

\subsection{Diagnosticeren}

De aan- of afwezigheid van een ziekte kan dus, inherent aan de beperkingen van een test, vrijwel nooit met $100 \%$ zekerheid

7. Zie S. Dekker, The field guide to understanding human error, Aldershot: Ashgate Publishing 2006 en ook S. Dekker, Patient safety, New York: CRC Press 2011. op grond van alleen de testuitslag worden vastgesteld. Maar hoe nu verstandig met deze onzekerheid om te gaan? De behandelend arts zal de uitslag van een test moeten interpreteren in het licht van de op dat moment al bekende gegevens, zoals de klachten van de patiënt en de eerder verkregen testresultaten. De diagnost dient dan niet alleen weet te hebben van die testkenmerken, maar tegelijk ook een idee te hebben van de kans op ziekte waarnaar wordt gezocht. Daarvoor bestaat een wiskundige benadering, het bayesiaanse model, dat het mogelijk maakt de kans op ziekte gegeven het testresultaat en de actuele ziektekans te berekenen. Maar dat wordt praktisch maar weinig gedaan, de meeste artsen gaan meestal meer intuïtief te werk. Trouwens, we komen dezelfde problematiek van juist omgaan met diagnostische onzekerheid ook tegen tijdens het feitenonderzoek in het strafrecht. ${ }^{8}$ En ook daar worden diagnostische fouten gemaakt!

Als diagnostische missers inherent aan de beperkingen van de tests zijn, is een misslag in juridische zin niet overduidelijk het gevolg van toerekenbaar tekortschieten van de zorgverlener. Zoals een deskundige het tijdens een procedure bijvoorbeeld voor de radiodiagnostiek omschreef:

'Een radiologische beoordeling is een onderdeel van het medisch handelen in het algemeen. Een goede radioloog mist zaken, maar behoort vervolgens goed aanspreekbaar te zijn als zijn beoordeling niet past in het geheel.'

De radioloog is voortdurend feilbaar en de laatste zin verwijst naar de zojuist besproken noodzaak elke uitslag kritisch te interpreteren in het licht van de op dat moment bekende of bekend geworden informatie.

Omdat er een immens arsenaal aan diagnostische mogelijkheden bestaat - meer dan tienduizend tests - moet de arts daaruit niet alleen gericht kiezen, maar ook bepalen wanneer het moment is om met diagnostiek te stoppen. Het begin van de diagnostiek wordt bepaald door het initiatief van de patiënt vanwege diens klachten of ziekteverschijnselen. Die kunnen aspecifiek zijn, zodat die geen duidelijke diagnostische route aanduiden, of zelfs misleidend, waardoor de verkeerde diagnostiek wordt ingezet. Er kan bij de arts het gevoel bestaan dat de zaak rond is en hij kan stoppen met de diagnostiek, waarbij achteraf blijkt dat dit onterecht is - de 'premature closure'. ${ }^{10}$ Het startpunt, de route en de finish van het diagnostische proces moeten bewust worden onderzocht bij een retrospectieve beoordeling van een vermeende diagnostische fout. Uit het voorgaande mag duidelijk zijn dat het stellen van de juiste diagnose voor iedere arts beslist een opgave is. ${ }^{11}$

8. D. Aben, De facto, RMThemis 2010, afl. 5/6, p. 223-233.

9. Rb. Zwolle-Lelystad 7 november 2007, ECLI:NL:RBZLY:2007: BC7015.

10. E.S. Berner \& M.L. Graber, Overconfidence as a cause of diagnostic error in medicine, The American Journal of Medicine (121) 2008, afl. 5A, p. S2-23.

11. R.L. Wears, What makes diagnosis hard?, Advances in health sciences education: theory and practice (14) 2009, Suppl. 1, p. 19-25. 


\section{Diagnostische fouten}

Hoe komen diagnostische fouten aan het licht? Het startpunt voor een civiele of tuchtrechtelijke procedure is steeds een voor de patiënt ongewenste uitkomst - zie alle hierna genoemde voorbeelden uit de jurisprudentie. Twijfel aan de juistheid van een eerder gestelde diagnose ontstaat door informatie die later beschikbaar is gekomen; er is dus steeds een terugkoppelingsmechanisme nodig om een misslag vast te kunnen stellen. Bijvoorbeeld: een vrouw wordt geopereerd omdat bij haar borstkanker was vastgesteld, maar na haar chirurgische behandeling toont onderzoek van het operatiepreparaat echter een goedaardige afwijking: er is een discrepantie tussen die twee, dus hier klopt iets niet. Dat kon worden verklaard doordat bij het eerste diagnostisch onderzoek er in het laboratorium van een verwisseling van haar biopten met die van een andere patiënt sprake bleek te zijn. ${ }^{12}$

Om de kwaliteit van diagnostiek te verbeteren wordt ervoor gepleit actiever te zijn met het - liefst systematisch opsporen van diagnostische fouten, om ze vervolgens te analyseren en ervan te kunnen leren. ${ }^{13}$ Overigens, door het beschikbaar komen en toepassen van steeds meer diagnostische onderzoeksmethoden en door verbeteringen van de bestaande diagnostiek komen door die intensievere en betere diagnostiek al vanzelf meer fouten aan het licht die gemaakt werden in eerdere stappen van het onderzoeksproces. Bijvoorbeeld: bij een traumapatiënt wordt een fractuur op een gewone röntgenfoto gemist. Dat blijkt omdat er bij haar vanwege aanhoudende klachten aanvullend een CT-scan werd gemaakt, die alsnog een fractuur openbaarde die achteraf ook op de eerste foto zichtbaar bleek. ${ }^{14}$ Zo zijn diagnostische fouten meer zichtbaar geworden, maar daardoor ook meer 'vatbaar' voor juridische procedures.

Wanneer een diagnose achteraf onjuist blijkt te zijn, dan is de verleiding groot om bij wijze van oorzaak-gevolgredenering die foute uitkomst ook aan een fout werkproces van de arts toe te schrijven. Maar, zoals we al zagen, dat is vaak niet het geval. Wanneer is er dan wél sprake van een diagnostische fout in medische én in juridische zin? Dat vraagt om definiëring. De medische operationele definitie van een diagnostische fout is puur descriptief en omschrijft drie situaties: ${ }^{15}$

1. Er is sprake van een diagnostische fout als op het moment van de zorgvraag de diagnose onbedoeld niet werd gesteld, waardoor de behandeling werd vertraagd. Terugblikkend was in een vroegere fase eigenlijk wel voldoende informatie beschikbaar om die diagnose te kunnen stellen. In de Nederlandse jurisprudentie komen we deze oorzaak vaak tegen. Voorbeeld: een vrouw meldt zich op de afdeling spoedeisende hulp (SEH) met rugpijn en tintelingen in de benen, wordt onderzocht en na geruststelling met pijnmedicatie naar huis gestuurd. Korte tijd later raakt haar

12. Rb. Rotterdam 21 december 2011, ECLI:NL:RBROT:2011:BU8990.

13. G.D. Schiff, Minimizing diagnostic error: The importance of follow-up and feedback, The American Journal of Medicine (121) 2008, afl. 5A, p. S38-S42.

14. Rb. Den Bosch 8 februari 2012, ECLI:NL:RBSHE:2012:BV3743.

15. K.M. McDonald e.a., Patient safety strategies targeted at diagnostic errors, Annals of Internal Medicine (158) 2013, afl. 5, p. 381-389. onderlichaam geheel verlamd door het samendrukken van haar ruggenmerg door een grote hernia. De alarmerende symptomen (tintelingen) waren niet op de juiste waarde geschat. ${ }^{16}$

2. Er is sprake van een diagnostische fout als de classificatie onjuist is gebleken. Voorbeeld: een man meldt zich met een bloedende pukkel op de rug. De huisarts denkt aan een onschuldige ontsteking, verwijdert die plek chirurgisch en gooit het weggesneden materiaal in de prullenbak. Later blijkt dat het ging om een bloedende kwaadaardige moedervlek (melanoom), waaraan de patiënt uiteindelijk overleed. ${ }^{17}$ Een vrouw die net bevallen was, bemerkt een knobbel in haar rechterborst. Er wordt radiodiagnostisch onderzoek gedaan (mammografie en echografie), waarbij de tumor als goedaardig wordt beoordeeld. $\mathrm{Zij}$ wordt gerustgesteld. Pas dertien maanden later, als zij zich nogmaals laat onderzoeken, blijkt die knobbel toch kwaadaardig - borstkanker - en moet ze behandeld worden met chirurgie en chemotherapie. ${ }^{18}$ Allemaal voorbeelden van vertraging van de behandeling door een foute diagnose.

3. Er is sprake van een diagnostische fout als de diagnose werd gemist, dat wil zeggen als er géén diagnose werd gesteld. Voorbeeld: een man wordt door een internist wegens diarree die veroorzaakt werd door een bacterie behandeld en daarna ontslagen. Ruim een jaar later wordt deze man plots volledig blind. Dat blijkt het gevolg van een ooginfectie in het kader van sterk verminderde weerstand ten gevolge van een hiv-infectie. De internist had niet aan de mogelijkheid gedacht dat de darminfectie een uiting van een onderliggende aids zou kunnen zijn en derhalve verzuimd op hiv te testen. ${ }^{19}$ Een ander veelbesproken voorbeeld is het nalaten van noodzakelijk prenataal onderzoek bij baby Kelly. ${ }^{20}$

In essentie komt het neer op twee mechanismen: of de diagnose werd niet op het juiste moment gesteld, of ze bleek onjuist. Mogelijke gevolgen: een behandeling werd niet gegeven, kwam te laat of was verkeerd. Maar een civiele procedure eist vervolgens de stap van descriptief naar normatief: een fout in juridische zin impliceert dat die medische fout steeds toerekenbaar is, omdat de arts verwijtbaar onzorgvuldig handelde. Hoe dat vast te stellen?

\section{Wat is er bijzonder aan diagnostische fouten?}

Als het gaat om zorggerelateerde letselschadezaken, wat is er dan anders aan het onderzoek van een diagnostische in vergelijking met een therapeutische dwaling? Bij een diagnostische misslag gaat het veeleer om het beoordelen van het complete werkproces - dus onbepaalder -, terwijl de therapeutische kwesties meer gaan over de juiste uitvoering van een omschreven interventie of het op gepaste wijze uitvoeren van een

16. Hof Arnhem 21 januari 2009, ECLI:NL:GHAMS:2009:BI2105.

17. Rb. Den Haag 31 december 2008, JA 2009/31 m.nt. R.W.M. Giard.

18. Hof Den Bosch 20 juli 2010, ECLI:NL:GHSHE:2010:BN2030.

19. Rb. Rotterdam 14 april 2010, ECLI:NL:RBROT:2010:BN7297.

20. HR 18 maart 2005, NJ 2006/606 m.nt. J.B.M. Vranken. 
bepaalde behandeling - dus gerichter. Ik zal die verschillen verder proberen te verduidelijken aan de hand van het vaste juridische stramien voor het vestigen van aansprakelijkheid voor zorggerelateerde schade: (1) onderzoek naar onzorgvuldigheid of tekortkoming in de nakoming, (2) het vaststellen van schade en (3) het causale verband tussen onrechtmatigheid en schade.

\subsection{Onderzoek naar onrechtmatigheid}

We hebben gezien dat bij diagnostiek elk menselijk oordeel of elke technische test elementair feilbaar is en dus zullen - tot schrik en ongenoegen van de patiënt - diagnosefouten beslist vóórkomen. In een civiele procedure wordt niet de test maar de arts ter verantwoording geroepen. Hoe stellen we nu zo objectief mogelijk vast of deze arts, gegeven de situatie, gepast handelde dan wel toerekenbaar tekortschoot? Waar ligt de grens tussen die twee? En hoe nauwkeurig en reproduceerbaar is dat oordeel? Dat normatieve oordeel blijkt niet eenvoudig, want we dienen ons te realiseren dat bij het welslagen van een diagnostisch proces zowel individuele als contextuele en systeemfactoren tegelijk een rol spelen.

\section{Individuele factoren}

Bij therapeutische interventies staat het medisch handelen of het nalaten daarvan centraal. Bij diagnostiek daarentegen draait het primair om het denken - de cognitieve functies van de individuele arts. Vandaar ook dat veel studies zich vanuit cognitief-psychologisch perspectief richten op denkfouten als oorzaak van diagnostische dwalingen. Het denkproces behelst het overwegen welke gegevens nodig zullen zijn om de aldus verkregen gegevens om te zetten in de gepaste diagnose: het proces van diagnostisch redeneren. De verkregen data moeten gericht worden verzameld, daarna worden geïnterpreteerd, en vervolgens dient een conclusie te worden getrokken. Dat vraagt kennis, vaardigheden en ervaring. ${ }^{21}$

Zo bezien wordt diagnosticeren als een expliciet en bewust uitgevoerd proces beschouwd. Echter, sinds twee decennia is gebleken dat denkprocessen verlopen via twee verschillende wegen ('dual process theory'), via een automatisch-intuitief (systeem I) of een expliciet-analytisch systeem (systeem II). Die systemen, vooral het automatisch-intuïtieve, zijn niet onfeilbaar gebleken. We gebruiken dagelijks allemaal vooral systeem I. Het maken van diagnostische fouten kan vanuit dit perspectief worden verklaard en onderzoek heeft aangetoond dat het meestal niet gaat om fouten die door moedwilligheid of onzorgvuldigheid werden veroorzaakt, maar door denkfouten, want er zijn duidelijke patronen bij het maken van diagnostische fouten herkenbaar - te karakteriseren als 'nofault'. ${ }^{22}$ Cognitief-psychologisch onderzoek heeft bovendien

21. A. Rajkomar \& G. Dhaliwal, Improving diagnostic reasoning to improve patient safety, The Permanente Journal (15) 2011, afl. 3, p. 68-73.

22. D. Kahneman, Ons feilbare denken, Amsterdam: Uitgeverij Business Contact 2011 duidelijk gemaakt hoe complex het proces van diagnosticeren in wezen is. ${ }^{23}$

Een belangrijk punt betreft vanzelfsprekend ook de parate kennis waarover de arts beschikt of zou moeten beschikken alsmede praktische vaardigheden om alles vorm te geven en het proces met succes af te sluiten: was dat allemaal wel toereikend in de gegeven situatie?

\section{Contextuele factoren}

Elk diagnostisch handelen vindt steeds plaats in een context en die bestaat uit verschillende elementen, zoals de klinische presentatie (de zieke, diens ziektebeeld en diens medische voorgeschiedenis), de uit die verschijnselen opgevatte taak die de arts zich stelt (is die concreet of ambigu?), de handelingssituatie (ongeval op straat, huisartsengeneeskunde, ziekenhuiszorg of superspecialistisch centrum) en de wisselwerking tussen de arts en de patiënt. Het proces kan zich in alle rust afspelen of in de hectiek van een overvolle SEH. Het medisch handelen voltrekt zich steeds binnen een wetenschappelijke context met zijn inherente mogelijkheden, maar ook beperkingen. Er is ten slotte ook een maatschappelijke context, die verwachtingen koestert over het functioneren van de arts en de zorg. Bij een procedure is onderzoek van al dergelijke contextuele factoren daarom onontbeerlijk. ${ }^{24}$

\section{Systeemfactoren}

Ten slotte zijn er nog structurele aspecten: de organisatie van het werkproces binnen het systeem van zorg. Het diagnostische proces is niet eenvoudig te beschouwen als een eenmalige handeling van één arts bij één patiënt. In veel gevallen gaat het om een werkwijze die uit vele achtereenvolgende stappen bestaat, waarbij dit proces bovendien steeds ingebed ligt in een groter systeem van zorg. Dat betekent dat diagnostiek zich afspeelt op meerdere plekken en op verschillende momenten, waarbij veelal ook meerdere personen betrokken zijn. Daardoor hebben we te maken met de effecten van multiple interacties tussen de patiënt en diens behandelaars, geconsulteerde ondersteunende specialisten (bijvoorbeeld radiodiagnosten en pathologen) en hulppersoneel. Dat speelt zich af binnen organisatorische structuren met de daarin aanwezige faciliteiten en de heersende cultuur.

Als er bij het diagnostische proces iets fout blijkt te zijn gegaan en beoordeeld moet worden of er sprake is van onzorgvuldig handelen, vragen deze individuele, contextuele en structurele factoren alle drie systematisch om aandacht tijdens het zoeken naar een causale verklaring voor die onheilsgebeurtenis. Dat kan, zoals eerder gesteld, niet uit de foutieve uitkomst worden afgeleid. Dan zullen we steeds vanaf het beginpunt het gehele diagnostische proces stap voor stap moeten gaan nalopen en bezien vanuit de genoemde drie perspectieven. Dan pas kunnen we beoordelen of er wel of niet juist door de arts

23. P. Croskerry, Clinical cognition and diagnostic error: Applications of a dual process model of reasoning, Advances in health sciences education: theory and practice (14) 2009, Suppl. 1, p. 27-35.

24. P. Croskerry, Context is everything or how could I have been that stupid?, Healthcare Quarterly (12) 2009, p. 171-176. 
werd gehandeld, en mogen we bovendien niet in de valkuil van wijsheid achteraf geraken. ${ }^{25}$ De methoden voor het onderzoek naar de feiten zullen daarop moeten worden afgestemd. ${ }^{26}$

De eerste, hierboven genoemde, definitie van een diagnostische fout is als het moment van diagnose onbedoeld werd vertraagd, terwijl er terugblikkend in een vroegere fase al voldoende informatie beschikbaar was om die diagnose wél te stellen. De meeste claims in ons land gaan over deze categorie. Maar is het in eerste instantie niet herkennen bij een traumapatiënt van een botfractuur verwijtbaar tekortschieten? ${ }^{27}$ Is het een huisarts te verwijten dat deze bij een ziek kind de diagnose bacteriële hersenvliesontsteking heeft gemist? ${ }^{28}$ Was bij een 37-jarige vrouw de diagnose hartinfarct al eerder te stellen geweest, waardoor ze geen hartschade zou hebben opgelopen? ${ }^{29}$ Bij dergelijke afwijkingen zijn de ziekteverschijnselen meerduidig en is een juiste diagnose vaak meer geluk dan wijsheid.

Geen casuspositie is normatief goed te beoordelen als niet eerst wordt vastgesteld wat hier de kern van het diagnostische probleem is. Was de kwestie zoals gepresenteerd in de klinische context bij deze patiënt vanaf het begin af karakteristiek voor de ziekte of was het beeld juist non-specifiek? Of werd de arts door de klachten van de patiënt op het verkeerde been gezet en werd er daardoor een - achteraf - onjuiste diagnostische route gekozen?

Geen enkele foutenkwestie is uniek: dat specifieke diagnostische probleem is eerder voorgekomen en meestal al wetenschappelijk onderzocht, dus dienen we dit 'unieke' probleemgeval tegen deze achtergrondinformatie in breder perspectief te beoordelen. Hoe vaak komt dit probleem voor? Waardoor wordt het veroorzaakt? Bijvoorbeeld radiodiagnostisch gemiste fracturen bij traumapatiënten op de SEH blijken frequent voor te komen. ${ }^{30}$ Waarom worden die dan zo vaak gemist? Jonge vrouwen, zoals onze 37 -jarige patiënt, blijken hun hartinfarct vaak zeer aspecifiek te presenteren. ${ }^{31}$ De diagnose hersenvliesontsteking is zeer zeldzaam en blijkt bij jonge kinderen bovendien geen kenmerkende ziekteverschijnselen te geven. Allemaal verklaringen waarom de diagnose werd vertraagd of gemist.

Maar wanneer is de diagnostiek van de hulpverlener nu juridisch beneden de maat? De juiste beantwoording van die vraag vraagt dus een breed en diepgaand onderzoek. Dat zal vaak uitgevoerd gaan worden door een deskundig beroepsgenoot, die dan ook dient te weten hoe een dergelijk onderzoek moet

25. Zie Giard 2010.

26. R.W.M. Giard, Waarheidsvinding. Hoe de juridische werkelijkheid het methodologische ideaal kan naderen, Trema (36) 2013, afl. 3, p. 89-96.

27. Zie noot 14 .

28. Rb. Zutphen 29 augustus 2002, ECLI:NL:RBZUT:2002:AE7282.

29. Rb. Utrecht 8 december 2010, ECLI:NL:RBUTR:1010:BO6888.

30. C.J. Wei e.a., Systematic analysis of missed extremity fractures in emergency radiology, Acta Radiologica (47) 2006, afl. 7, p. 710-717 en R. Pfeifer $\&$ H.C. Pape, Missed injuries in trauma patients: A literature review, Patient Safety in Surgery 2008, afl. 2, p. 20.

31. B. Xhyheri \& R. Bugiardini, Diagnosis and treatment of heart disease: Are women different from men?, Progress in Cardiovascular Diseases (53) 2010, afl. 3, p. 227-236. worden aangepakt. ${ }^{32}$ Essentieel daarbij is het voorleggen van de juiste vraagstelling aan de deskundige. Omdat het normatieve oordeel berust op een causale verklaring van de onheilsgebeurtenis, is juist het stellen van open onderzoeksvragen aan de expert daarbij zo belangrijk. ${ }^{33}$

\subsection{Onderzoek naar de schade}

De schade is het startpunt van de procedure. Er kan sprake zijn van twee categorieën juridisch relevante schadelijke gevolgen van een diagnostische fout:

1. Een bestaande ziekte wordt niet of niet bijtijds ontdekt en daardoor wordt er niet of niet tijdig behandeld.

2. Een niet-bestaande ziekte wordt gediagnosticeerd en als zodanig behandeld, wat echter onnodig is.

Wat betreft de eerste categorie: het gaat dan om ziekteprocessen waarbij door een vertraging of uitblijven van de diagnose de kans op genezing afneemt of zelfs verkeken is. Wanneer de diagnose van een kwaadaardig gezwel van de alvleesklier bij een vrouw met buikklachten eerder zou zijn gesteld, zou zij ook eerder zijn behandeld. ${ }^{34}$ Tweede voorbeeld: een vrouw neemt deel aan het bevolkingsonderzoek naar borstkanker. Er wordt bij haar geen afwijking gevonden, maar enkele maanden later blijkt ze toch borstkanker te hebben. Het gaat hier - anders dan bij de vorige patiënt - niet om symptomatische diagnostiek, maar om vroegdetectie van een tumor bij een vrouw zonder ziekteverschijnselen. Hierbij komt weer om de hoek kijken of de test nu bedoeld was om met zekerheid kanker aan te tonen of uit te sluiten. Bij kankerscreening is uitsluiten van ziekte beslist niet het doel. Bij beide voorbeelden is het, omdat het om kanker gaat, denkbaar dat de schade bestaat uit verlies van een kans op een beter resultaat door de verlate behandeling. ${ }^{35}$ De schade is hier virtueel.

Wat betreft de tweede soort schade: een verkeerde diagnose leidt tot een verkeerde behandeling. Wordt de diagnose borstkanker ten onrechte gesteld (zie het hierboven genoemde voorbeeld $\left.{ }^{36}\right)$, dan volgt een meestal ingrijpende maar onnodige chirurgisch-oncologische behandeling. De schade is hier merkbaar en dus concreet.

\subsection{Het causale verband}

Zoals reeds gesteld, spelen bij de eiser van meet af aan causale percepties een belangrijke rol. $\mathrm{Bij}$ de juridische procedure echter vormt de causaliteit meestal juist het sluitstuk; na het vaststellen van onzorgvuldig handelen van gedaagde en het constateren van schade bij de gelaedeerde volgt het onderzoek naar het causale verband tussen die twee. Maar bij het bepalen van het conditio sine qua non (CSQN)-verband kan het juist bij

32. R.W.M. Giard, Medische expertise bij diagnostische missers, Expertise en Recht 2008, afl. 2, p. 56-64

33. R.W.M. Giard, De opdracht aan een deskundige: de kracht van het stellen van open vragen, Expertise en Recht 2013, afl. 2, p. 50-58.

34. Rb. Amsterdam 18 mei 2011, ECLI:NL:RBAMS:2011:BQ6524.

35. Rb. Zwolle-Lelystad 8 september 2004, ECLI:NL:RBZLY:2004: AQ9892; Hof Arnhem 17 januari 2006, JA 2006/37 m.nt. R.W.M. Giard.

36. Zie noot 12 
diagnostische misslagen flink fout gaan. ${ }^{37} \mathrm{Bij}$ dit gedachteexperiment wordt de causale factor - de onrechtmatigheid of het tekortschieten - 'weggedacht' en vervolgens bezien of het schadegevolg dan ook zou zijn ingetreden. Dat impliceert steeds dat tijdens de procedure een oorzakelijk moment in de hele keten van gebeurtenissen is komen vast te staan - het proces van causale selectie. De eisende partij stelt dat als door de arts de juiste diagnose op het juiste moment zou zijn gesteld, het schadegevolg zou zijn uitgebleven, en hier ligt de fundamentele attributiefout op de loer. Hebben we wel het juiste causale moment te pakken of is hier eerder sprake van een causaal netwerk?

In de procedure van de bij screening gemiste diagnose borstkanker ${ }^{38}$ werd de onrechtmatigheid bewezen geacht omdat de deskundige wél afwijkingen zag, die de radioloog in eerste instantie niet had opgemerkt: dat was dus het causale moment, want was de afwijking wél gemeld, dan zou er vervolgonderzoek hebben plaatsgevonden en zou de tumor zeer waarschijnlijk eerder zijn ontdekt. Diverse onderzoeken hebben inmiddels het belang aangetoond van blinde (dus zonder voorkennis van de gemiste diagnose) herbeoordeling van röntgenfoto's. ${ }^{39} \mathrm{Bij}$ een dergelijke objectiverende herbeoordeling blijkt steeds dat de meeste 'afwijkingen' opnieuw gemist worden. Daarmee wordt de causale betekenis van het handelen van de radioloog, diens onterecht 'missen' van de afwijking, sterk in twijfel getrokken: het gaat in de screeningssituatie om intrinsiek moeilijk te detecteren afwijkingen. Dat 'missen' van borstkanker bij screening blijkt frequent voor te komen: bij meer dan een kwart van de gescreende vrouwen wordt hun borstkanker buiten de screening om ontdekt en als dat zo regelmatig voorkomt, duidt dat eerder op een problematiek die eigen is aan deze speciale vorm van diagnostiek. ${ }^{40}$

Het leveren van het bewijs van het CSQN-verband bij concrete schade zal minder problemen opleveren dan wanneer er van kansschade sprake is. ${ }^{41} \mathrm{Bij}$ de genoemde voorbeelden over de te laat of niet-gestelde diagnose kanker is dat lastig. Er kan sprake zijn van een verlies van kans op een beter behandelingsresultaat, maar is er methodologisch juist uitgevoerd empirisch onderzoek beschikbaar waaruit blijkt of, en zo ja, hoeveel kansverlies er dan is opgetreden? Een dergelijke benadering kan ook worden toegepast voor niet-oncologische problemen, bijvoorbeeld het missen van een dreigende dwarslaesie bij een traumapatiënt, die later verlamd rakte. ${ }^{42}$

Voor de eiser is juist bij kansschade het leveren van het bewijs van het CSQN-verband problematisch. De leerstukken van de proportionele aansprakelijkheid, bewijslastvermindering en de omkeringsregel kunnen uitkomst bieden, maar hun

37. Zie Giard 2010

38. Zie noot 35 .

39. A.F. Fotenos e.a., Unbiased review of digital diagnostic images in practice: Informatics prototype and pilot study, Academic Radiology (20) 2013, afl. 2, p. 238-242.

40. V. van Breest Smallenburg e.a., Malpractice claims following screening mammography in the Netherlands, International Journal of Cancer (131) 2012, afl. 6, p. 1360-1366.

41. Zie Wijne 2013, p. 419 e.v.

42. Rb. Haarlem 1 maart 2006, ECLI:NL:RBHAA:2006:AV5277. toepassing is aan strenge regels onderhevig. ${ }^{43} \mathrm{Bij}$ diagnostische fouten zal vooral het leerstuk van de kansschade van toepassing zijn. ${ }^{44}$

\section{Conclusies}

Het stellen van een diagnose is in veel gevallen een complex proces en door de inherente beperkingen van zowel elke test als de cognitieve functies van de diagnost daarom ook steeds potentieel feilbaar. Als het misgaat, is het niet per definitie de schuld van de dokter. Uit het bovenstaande moge duidelijk zijn dat het onderzoek naar de verwijtbaarheid van diagnostische missers vraagt om een brede opzet, met aandacht voor zowel de individuele als de contextuele en de organisatorische aspecten. Het is een ander soort problematiek dan fouten bij de behandeling. Bij het onderzoek naar diagnostische dwalingen moeten we niet alleen kijken naar de gedragingen van de arts, maar ons breder oriënteren; de spade zal gewoon dieper gestoken moeten worden!
43. A.J. Akkermans \& Chr.H. van Dijk, Proportionele aansprakelijkheid, omkeringsregel, bewijslastverlichting en eigen schuld: een inventarisatie van de stand van zaken, AV\&S 2012, afl. 5, p. 157-177 en Chr.H. van Dijk, Causale perikelen: het is moeilijk en zal moeilijk blijven, TVP 2013, afl. 3, p. 61-84.

44. C.J.M. Klaassen, Kansschade en proportionele aansprakelijkheid: volgens de Hoge Raad geen zijden van dezelfde medaille, AV\&S 2013/14.1. 